\title{
Using twitter to elicit the patient perspective
}

\author{
Katherine A Margolis ${ }^{1}$, Laura Catalusci ${ }^{2}$ Jacqueline Cleary $^{3}$ \\ ${ }^{1}$ InVentiv Health Newtown, PA \\ ${ }^{2}$ Draftfcb Healthcare New York, NY \\ ${ }^{3}$ Jersey City, USA
}

Email address:

katherineamargolis@gmail.com (K. A Margolis)

\section{To cite this article:}

Katherine A Margolis, Laura Catalusci, Jacqueline Cleary. Using Twitter to Elicit the Patient Perspective. American Journal of Health Research. Vol. 2, No. 1, 2014, pp. 1-8. doi: 10.11648/j.ajhr.20140201.11

\begin{abstract}
The social media platform, Twitter, was used to understand the patient perspective on experiences with asthma. A content analysis of 844 tweets was conducted. The sample of tweets was obtained by performing a keyword search over the course of a one week period. The categories for coding were established based on a literature review. The most frequently occurring theme to emerge in the data was general disease state $(n=115,13.7 \%)$. The next most frequently found themes included triggers of asthma $(n=100,11.8 \%)$ and general treatment $(n=95,11.2 \%)$. Asthma was often discussed in a joking manner and tweets were utilized to share medical information. Results proved that Twitter can serve as a valuable research tool to understand how people communicate about health topics.
\end{abstract}

Keywords: Asthma, Twitter, Patient Perspective, Health, Content Analysis, Social Media

\section{Introduction}

Asthma, a chronic inflammatory disorder affecting the air passages leading to and from the lungs [1], is one of the world's most preventable chronic diseases [2]. According to the World Health Organization (WHO), nearly 235 million people currently suffer from asthma worldwide. It is also the most common chronic disease among children [3]. Furthermore, the rate of asthma diagnosis is on the rise. The prevalence of asthma increased by $12.3 \%$ in the United States from 2001 to 2009 , to reach a total of 24.6 million individuals in the US currently diagnosed with asthma [4].

Asthma symptoms are typically characterized by inflammation of the bronchial airways resulting in recurrent episodes of wheezing, breathlessness, chest tightness, and coughing [1] of the individuals diagnosed with asthma in the U.S., over $60 \%$ are able to recognize early signs and symptoms of an asthma attack and respond appropriately with follow-up treatment [4]. However, there is still opportunity to increase sign and symptom recognition among diagnosed individuals to improve treatment rates. Lack of proper asthma treatment has been linked to high morbidityand significant mortality rates [2]. Therefore, most asthma-related deaths are preventable and related to delay in treatment or suboptimal medical care [2].

Recognition of the signs and symptoms of an asthma attack are crucial to decreasing high morbidity and mortality rates as well as improving the quality of life (QoL) for those diagnosedwith asthma. The severity and presence of asthma symptoms are known factors that affectQoLfor individuals with asthma and their families $[5,6]$. Asthma attacks can cause considerable QoL burden and strain that may last a lifetime [7]. However, the determinants of low health-related QoL are not well understood [8]. One study identified that some of the determinants that are significantly associated with QoL in individuals diagnosed with asthma include: gender, smoking behavior, airway responsiveness to irritants, severity of asthma symptoms, and absenteeism from work/school [8]. In fact, 41.8\% (4.6 million) of the patients self-reporting the burdens related to having an asthma attack indicatedthat they missed greater than or equal to 1 day(s) of school or work within a one year period[4]. On average, 4.5 days of school or work per year were missed per individual [4]. Visiting an emergency department or urgent care center was reported by $26.0 \%$ (3.2 million persons) [4].Admission to the hospital was reported by $7.0 \%$ [4].Additionally, nearly 1 out of seven individuals required urgent outpatient care [4]. These burdens have also been linked to depression, anxiety and emotional disorders, which may further decrease an individual's QoL if asthma management and treatment is not adequate [5].

Over an individual's lifetime, the burden caused by asthma addssubstantial costs both to the individual and to 
society. The medical expenses for asthmas are approximately $\$ 3,259$ per person a year for a total cost to society of $\$ 50.1$ billion per year. Loss of productivity (e.g., missed school or work days) adds to these costs and is approximately $\$ 3.8$ billion per year (Barnett \& Nurmagambetov, 2011). To help overcome the burden of individuals and society, it is important to support selfmanagement of asthma and focus on prevention of asthma attacks among individuals diagnosed with asthma [4]

\section{The Patient Perspective - Adherence and Asthma Issues}

The goal of asthma treatment is to manage the disease by controlling symptoms. This requires the patient to take an active role by developing a treatment plan with his or her physician. Treatment plans can be complex and may include: taking medications as prescribed, avoiding triggers that can worsen asthma symptoms, tracking perceived level of asthma control, and seeking emergency help when needed [9]. Typically, pharmacologic therapy for asthma consists of controller medications, used to maintain control of asthma symptoms, such as an inhaled corticosteroids, and quick-acting medications used for acute episodes of asthma [10]. Relying on patients to comply or adhere to their medications and treatment plan can pose challenges.

Adherence has been defined as "the extent to which a person's behavior corresponds with recommendations from a health care provider" [11]. On average, at least $50 \%$ of patients with asthma are non-adherent to maintenance medications [10]. Non-adherence to asthma treatment can result in increased mortality, morbidity, and higher healthcare costs [11].

There are intentional and unintentional reasons patients are non-adherent to asthma treatment. Unintentional reasons may include inadequate training on how to properly use an inhaler or a lack of understanding about the need for preventative medicine[11].Intentional non-adherence may result from anxiety about medication side effects, inconvenience of treatment regimen, especially with inhaler therapy, forgetfulness or carelessness[11].Furthermore, one study found that $31 \%$ of patients reported forgetting to take their controller medication "a couple of times every month" [12].

Patient adherence can be difficult to measure and often relies on electronic device monitors, pharmacy records, clinical judgment, and patient self-report [11]. The Expert Panel Report (EPR) Guidelines for physicians recommends encouraging patients to use self-assessment tools like diaries or periodic self-assessment forms. This helps patients track their perceived level of control over their asthma symptoms and helps the physician gain an understanding of the patient perspective [1]. Not only is a patient's perceived sense of control important to understand, but studies have also shown perceived severity of disease as an important factor in adherence[11, 12]. There is a significant association between an increase in patient's perceived severity of asthma and a decrease in accidental and intentional non-adherence to controller therapy [12]. This may mean that patients who perceive their asthma as more severe are more likely to take their inhaler on a regular basis than those patients who perceive their asthma as mild [12].

Understanding patient perspectives on the challenges associated with adherence, perceived level of control, and perceived level of severity has the potential to lead to improved educational interventions and as a result, improved adherence rates. Garnering the patient perspective can be accomplished through many different research methods and can help to highlight opportunities for improving the patient experience and thus, the potential for an improved quality of life for asthma sufferers.

\section{Social Media as a Tool for Gaining the Patient Perspective}

Traditional methods of gaining the patient perspective often include research techniques such as questionnaires, focus groups, interviews and patient shadowing [13]. Studies soliciting patient perspectives are often associated with limitations as a result of using these traditional research methods. Limitations can often be associated with subjectivity, in which either the researcher or the research participant may influence the study results for various reasons [14]. For example, the solicitation of study participants presents a level of partiality due to the possibility of selection bias, where the sampling procedure favors selection of some individuals over others [15]. Additionally, an overarching limitation of traditional research methods is patient recall bias. Recall bias occurs when patients have an inaccurate recollection of their experiences related to their health or disease state, which then influences their reported perspective [14].

Social media is an underleveraged resource of patient perspectives for the healthcare industry [16]. Utilizing social media as a tool to gain the patient perspective can help overcome the limitations of traditional research methods. Social media serves as a network that allows individuals to express their perspective in the moment they wish to express it [17]. Patients can easily update their status or share information with their social peers in an instant. This instantaneous sharing is further supported by the convenience of providing updates via mobile devices; thus, potentially capturing patient perspectives in real-time. This real-time sharing of information appears to help reduce the recall bias that is often associated with other research efforts.

Collaboration, the sharing of personal ideas, thoughts and interests are all encouraged through the use of the social media networks. In the case of patients who choose to share their information via social media, the information they choose is usually unfiltered and often unsolicited. In 
fact, patients who choose to share their information in a public setting may not be aware that their information can be collected for research purposes. This is unlike traditional research methods in which patients are aware that they are participating in a study leading to potential bias.

Further, since social networks are supported by the internet, this allows patients of all demographic backgrounds and varied disease-states from all over the world to share health related information with and connect to others like themselves [16]. As social media can collect data from all patients to gain the patient perspective, selection bias may be minimized when conducting research using social media as a source of data.

Using Twitter as a social media source, this study aims to help overcome the limitations of traditional methods of gaining the patient perspective of asthma. As more patients engage with social media, an opportunity grows to monitor, interpret, and respond [18] to the gained patient perspective with the goal of enhancing the patient experience and improving health outcomes through this novel research approach.

\subsection{The Emergence of Twitter}

Twitter is a real-time information network that connects people to the latest stories, ideas, and opinions most interesting and useful to them. Twitter is based on users providing information through tweets which can be up to 140 characters long[19, 20]. They allow users to share information along with photos, videos, and articles that direct followers to even more information (http://twitter.com/about). People can choose to follow individuals, organizations, and even businesses on Twitter based on their interests.

There are 140 million active users on Twitter and more than 340 million tweets per day [19]. Approximately 25.6 million of Twitter users are accessing the social media site via mobile devices [21]. With access to Twitter from mobile applications on a smartphone, like an IPhone or Blackberry, the ability to tweet remotely is increasingly acceptable practice.

Twitter allows users to search by topic to quickly find what people and organizations are posting about in regards to that topic. In order to find relevant topics, users can search via a hashtag symbol, \#. Hashtag symbols also allow Twitter users to organize themselves into groups [20]. For example, a patient interested in learning more about what other Twitter users are saying about asthma would search on Twitter with \#asthma. This search aspect and the fact that Twitter is real-time and open to the public provides another venue to gain insight into people's thoughts, opinions, and experiences in regards to a particular subject like asthma.

\subsection{Twitter as a Research Tool}

The internet has increased patient's access to health information, but the aspect of social networking and the emergence of Facebook, Twitter, and blogs have helped facilitate patients reaching out and finding others like them. In fact, one in five internet users have gone online to find others with similar health conditions to theirs [22]. Internet users who have experienced a recent medical emergency are also more likely than other internet users to go online to try to find someone who has also been through the same situation (23\% vs. 16\%)[22]. Asthma certainly is a condition that warrants reaching out and finding support from peers. The use of social media sites like twitter could be enhanced with a medical emergency like an asthma attack.

This leads to the research questions for this study:

Research Question 1: What are the most frequently mentioned topics related to asthma on twitter?

Research Question 2: What can twitter tell us about the patient experience with asthma?

\section{Methods}

In order to answer these research questions, a literature review analysis was conducted prior to the data analysis to understand the patient experience with asthma. The findings of the literature review analysis informed the search terms used to pull a cross-section sample of tweets related to the patient experience with asthma. A program called Topsy (www.topsy.com) was used to search for one week (9/30/12 to $10 / 6 / 12)$ of Twitter data, or tweets. The advanced search feature was used to search for a representative sample of tweets using keywords from a predefined time range. A predefined time range was used as a method for segmenting the data. The following terms were used as keywords for the search: asthma attack, asthma medication, asthma medicine, asthma inhaler, asthma treatment, asthma trigger, and asthma symptom. This resulted in 1066 tweets. When the duplicate and spam tweets were removed, 844 tweets remained for content analysis and coding.

The resultant data set was analyzed using an exploratory thematic analysis strategy as outlined by Guest, MacQueen and Namey [23]. Exploratory thematic analysis was used to ensure that the analysis was content-driven and because this is a new area of research without established criteria.

In order to establish a codebook to analyze the data, emergent coding based on a sample data set was used. This data set contained tweets obtained by using the same aforementioned search terms but used a different time range. This resulted in a pool of sample tweets that were used to develop a codebook in an iterative fashion.

Additional insights from the literature review process were used to inform the coding categories and thematic descriptions. In general, the following criteria were used to establish a theme: repetition of a theme in the data, metaphors and analogies, constant comparison and silence/missing data. The final coding system contained phrases or words as show in the coding categories and thematic descriptions mentioned inTable 1. 
Two independent coders analyzed the data. In order to establish reliability between the coders, the sample tweet pool was used. Each coder using the established codebook and an exploratory thematic analysis strategy then analyzed these sample tweets. In order to establish intercoder reliability between the two coders, 100 sample tweets were selected. Each of the coders then analyzed the data and assigned codes based on the categories. Any disagreement about the codes was discussed until consensus was reached. This was repeated for three rounds until the two independent coders had substantial agreement. The content of over 500 tweets was systematically analyzed by two independent coders in rounds of 100 tweets until thematic saturation was achieved and intercoder reliability reached an acceptable level. The measured Cohen's Kappa for the sample data was .62, indicating an acceptable level of agreement.

With reliability established, the 844 remaining tweets were then randomly divided in half and each coder coded half of the data set independently.

Table 1: Code Categories and Thematic Descriptions

\begin{tabular}{|c|c|c|}
\hline \# & Theme & Thematic description \\
\hline 1 & General disease state & General inquiries about asthma, non-specific asthma tweets, or listing multiple asthma category areas \\
\hline 2 & Asthma prevalence & Prevalence in asthma in any population \\
\hline 3 & $\begin{array}{l}\text { Preventing or minimizing } \\
\text { asthma attacks }\end{array}$ & Sharing information and tips for minimizing or preventing an attack \\
\hline 4 & Risk factors for asthma & Highlights risk factors of asthma diagnosis \\
\hline 5 & Triggers of asthma & Highlights triggers for asthma symptoms or asthma attack \\
\hline 6 & Signs and symptoms & Discusses signs and symptoms of asthma \\
\hline 7 & Environment and air quality & Statement and/or concerns about environment or air quality that may be linked to asthma \\
\hline 8 & Experiencing an asthma attack & Occurrence or experiencing asthma attack \\
\hline 9 & $\begin{array}{l}\text { Feelings about symptoms, } \\
\text { asthma, or asthma attack }\end{array}$ & $\begin{array}{l}\text { Sharing thoughts, concerns, frustrations about asthma, symptoms or having an attack. Also seeking } \\
\text { validation from others }\end{array}$ \\
\hline 10 & General treatment & $\begin{array}{l}\text { General information or mention about asthma treatment (not specific to pharmaceutical or } \\
\text { complementary and alternative treatment) }\end{array}$ \\
\hline 11 & Pharmaceutical treatment & $\begin{array}{l}\text { Discussions and inquiry about types of Pharmaceutical treatments for asthma; includes: inhalers or } \\
\text { OTC, promotions of specific treatments, mentions of FDA }\end{array}$ \\
\hline 12 & Using pharmaceutical treatment & Learning how to properly use pharmaceutical treatment, including inhalers, dosing, etc. \\
\hline 13 & Mechanism of Action (MOA) & Learn how the medicine works \\
\hline 14 & Treatment side effects & Any mention or concerns of side effects resulting from treatment \\
\hline 15 & Treatment outcomes & $\begin{array}{l}\text { Any mention or concern about the outcomes of treatment (not related to quality of life). Examples: } \\
\text { benefits, efficacy, results }\end{array}$ \\
\hline 16 & $\begin{array}{l}\text { Complementary and alternative } \\
\text { treatment }\end{array}$ & $\begin{array}{l}\text { Discuss alternative treatment options to pharmaceuticals. Some examples include yoga and home } \\
\text { remedies }\end{array}$ \\
\hline 17 & Quality of life & $\begin{array}{l}\text { Negative and positive lifestyle effects: missed school days/work, effect on day-to-day activities, } \\
\text { unable to participate in activities, improvements, life changes }\end{array}$ \\
\hline 18 & Asthma and comorbid condition & Discusses asthma affecting another condition or vice versa \\
\hline 19 & Death & Death due to asthma attack \\
\hline 20 & Pregnancy & Information and concerns about asthma, symptoms, and treatment during pregnancy \\
\hline 21 & Programs and services & Asthma programs and services \\
\hline 22 & Joke & Using the terms asthma or asthma attack as a joke \\
\hline 23 & Stigma & Negative social perceptions of asthma \\
\hline 24 & Other & Tweets that do not fall in the categories listed, or tweets that are not interpretable but mention asthma \\
\hline 25 & Delete & Tweets that do not mention asthma and repeat tweets \\
\hline
\end{tabular}

\section{Results}

The first research question asked was what were the most frequently mentioned topics related to asthma on Twitter? Using the list of search terms generated by the literature review analysis, the tweets were compiled and thematic code analysis was conducted. Table 2 shows the search terms that were used and the number of tweets that each term produced. The search terms "asthma treatment" and "asthma symptom" produced the greatest number of tweets followed by "asthma attack."
Table 2: Number of Tweets Based on Search Terms

\begin{tabular}{ccc}
\hline Search Term & Number of Tweets & Percent \\
\hline Asthma treatment & 252 & 31.0 \\
Asthma symptom & 218 & 25.8 \\
Asthma attack & 146 & 17.3 \\
Asthma inhaler & 89 & 10.5 \\
Asthma trigger & 38 & 4.5 \\
Asthma medication & 20 & 2.4 \\
\hline
\end{tabular}


When the coding system was applied to analyze the data set, the most frequently occurring theme to emerge in the data was general disease state $(\mathrm{n}=115,13.7 \%)$. Table 2 shows the results of applying the coding system to the complete data set. Another commonly occurring theme in the data was treatment. To get a more nuanced understanding of tweets about treatment, "asthma treatment" was created as a category. In order to determine the total number of "asthma treatment" tweets, all treatment-related categories were collapsed to arrive at this number.For example, the data set showed commonly occurring themes about different treatment types. These themes and treatment types included general treatment $(\mathrm{n}=95,11.2 \%)$, complementary and alternative treatment $(\mathrm{n}=92,10.9 \%)$, and pharmaceutical treatment $(\mathrm{n}=65,7.7 \%)$. Together, these 3 individual treatment categories add up to a total of 252 or $29.86 \%$ tweets related to "asthma treatment." Less prevalent themes related to "asthma treatment" included 4 $(0.5 \%)$ tweets about treatment side effects, $7(0.8 \%)$ about using pharmaceutical treatment, 0 about the mechanism of action (MOA) and $6(0.7 \%)$ about treatment outcomes.

Afterconducting the content analysis, visual representations of the frequency of single words occurring in the three most frequent themes were generated (Fig. 1, Fig. 2, Fig. 3).

\section{treatment}

Figure 1: A Visual representation of the frequency of words that appeared in tweets about triggers of asthma.

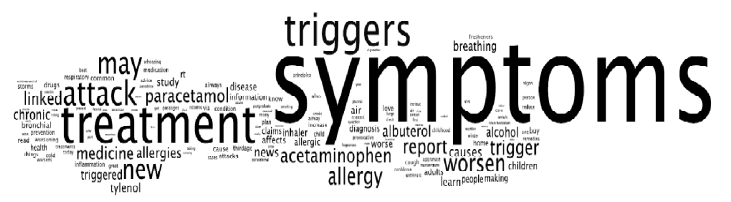

Figure 2: A Visual representation of the frequency of words that appeared in tweets about general disease state.

\section{Har. treatment symptoms}

Figure 3: A visual representation of the frequency of words that appeared tweets about general treatment.

These visual representations, called word clouds, are created by a program called Wordle that identifies the most frequent words in a portion of text and then represents them proportional to their frequency; the larger the representation of the word the more frequent it was used in a tweet. The word "Asthma" was deleted from all the tweets when generating the clouds as it would have always been the most frequent word because it was the base word for the searches conducted. Additionally, all links were removed because they presented no significance to this part of the study.

From the word clouds relationships can be drawn between the frequency of words and their themes. For example, in figure 1 representing theme one, general disease state, the words that correspond to the search for that theme directly (i.e.: treatment, symptoms, attack, albuterol, chronic...) are the most frequent.

In figure 2 representing theme 16 , complementary and alternative treatment, the words that correspond to the search for that theme directly (i.e.: treatments, remedies, alternative, cures...) are the most frequent, but some of the medium sized words such as "yoga" and "Chinese" are not directly related to the search but suggest a secondary theme existing among tweets about complementary and alternative treatment. This can be interpreted to signify that of the existing alternative remedies, yoga and Chinese remedies are two of the more popular solutions.

The second research question asked what Twitter can tell us about the patient experience with asthma. There were only 5 tweets $(0.6 \%)$ about quality of life and asthma. The data revealed that many were also using twitter to share medical information. Additionally, there were numerous tweets that included a link for more information or a follow-up piece of information. Links were included in $43.2 \%(n=365)$ of the tweets analyzed. An example of this type of tweet is, "Study: Cholesterol Drugs May Worsen Asthma - WebMD http://t.co/xveY98r4 \#medicine". Table 3 also includes an example of tweets found in the data set.

\section{Discussion}

Overall, most tweets were utilitarian in nature and focused on treatment, triggers and signs and symptoms. This highlights the idea that people are most concerned with how to treat and prevent asthma. Despite the rampant effects that asthma can have on quality of life, very few people tweeted about this $(n=5,0.6 \%)$. Very few people also tweeted about their feelings about symptoms, asthmas or asthma attacks $(n=6,0.7 \%)$. Therefore, people are turning to twitter to search and share information about treatment, symptoms, and triggers of asthma. Conversely, they are not using twitter as often to express their feelings or perceived limitations due to asthma.

Although people are not frequently using twitter to talk about quality of life issues, the data did reveal that twitter is being used as a source of medical information. People are directly sharing their own asthma knowledge and also retweeting relevant medical information and links. Twitter can effectively be used to understand patient questions and areas of concern. Patients may not always consult their healthcare practitioner for this. This may be due to a social desirability bias or a sense of urgency. Using Twitter to obtain and share medical information can afford an 
individual relative anonymity and result in quick and timely sharing of information.

This study showed that Twitter can be used as a valuable research tool to understand how and when people communicate about a particular topic. Although tweets are relatively short bits of information, they can be a useful and accurate data source as they are a natural expression of people in their natural settings. Tweets are not subject to any testing or laboratory effects that other studies may produce. Therefore, studies using tweets as data points are higher in ecological validity than laboratory studies. Another benefit of using Twitter as a data source is that it removes the selection bias that is inherent in any sort of study design with sampling. Due to the fact that all tweets from the global population are included, data is representative of those tweeting.

Table 3: Coding Results

\begin{tabular}{|c|c|c|c|c|c|}
\hline$\#$ & Category & Thematic description & Example & $\begin{array}{l}\text { Number of } \\
\text { Tweets }\end{array}$ & $\begin{array}{l}\text { Percent } \\
\text { age }\end{array}$ \\
\hline 1 & General disease state & $\begin{array}{l}\text { General inquiries about asthma, } \\
\text { non-specific asthma tweets, or } \\
\text { listing multiple asthma category } \\
\text { areas }\end{array}$ & $\begin{array}{l}\text { "\#asthma patients suffer from attacks that make } \\
\text { breathing difficult. Treatment requires decreasing } \\
\text { the symptoms of... http://t.co/UAMrW1pr" }\end{array}$ & 115 & 13.7 \\
\hline 2 & Asthma prevalence & $\begin{array}{l}\text { Prevalence in asthma in any } \\
\text { population }\end{array}$ & $\begin{array}{l}\text { "Asthma Treatment: Nearly nine million children } \\
\text { in the United States suffer from asthma, and } \\
\text { studies have shown that.." }\end{array}$ & 8 & 0.9 \\
\hline 3 & $\begin{array}{l}\text { Preventing or } \\
\text { minimizing asthma } \\
\text { attacks }\end{array}$ & $\begin{array}{l}\text { Sharing information and tips for } \\
\text { minimizing or preventing an attack }\end{array}$ & $\begin{array}{l}\text { "Asthma symptoms? Stay calm by belly } \\
\text { breathing: sit-up strght, breathe in deep thru nose } \\
\text { slowly, breathe out slow like blowing bubbles- } \\
\text { repeat" }\end{array}$ & 34 & 4.0 \\
\hline 4 & Risk factors for asthma & $\begin{array}{l}\text { Highlights risk factors of asthma } \\
\text { diagnosis }\end{array}$ & $\begin{array}{l}\text { "Symptoms of asthma worse in kids with low } \\
\text { vitamin D http://t.co/Aiwl hawa \#asthma } \\
\text { \#vitaminD" }\end{array}$ & 7 & 0.8 \\
\hline 5 & Triggers of asthma & $\begin{array}{l}\text { Highlights triggers for asthma } \\
\text { symptoms or asthma attack }\end{array}$ & $\begin{array}{l}\text { "Air fresheners can trigger allergies, asthma: } \\
\text { http://t.co/LiDoa0B4 via @msnbc } \\
\text { \#http://t.co/5kPdMpzy via@aacmaven.” }\end{array}$ & 100 & 11.8 \\
\hline 6 & Signs and symptoms & $\begin{array}{l}\text { Discusses signs and symptoms of } \\
\text { asthma }\end{array}$ & $\begin{array}{l}\text { "Can Wine provoke asthma and other allergy-like } \\
\text { symptoms." }\end{array}$ & 69 & 8.2 \\
\hline 7 & $\begin{array}{l}\text { Environment and air } \\
\text { quality }\end{array}$ & $\begin{array}{l}\text { Statement and/or concerns about } \\
\text { environment or air quality that may } \\
\text { be linked to asthma }\end{array}$ & $\begin{array}{l}\text { "Enhancing ventilation in homes of children with } \\
\text { asthma: cost-effectiveness study alongside } \\
\text { randomis... http://t.co/ZMbGQxvX } \\
\text { \#FamPractice" }\end{array}$ & 6 & 0.7 \\
\hline 8 & $\begin{array}{l}\text { Experiencing an asthma } \\
\text { attack }\end{array}$ & $\begin{array}{l}\text { Occurrence or experiencing asthma } \\
\text { attack }\end{array}$ & $\begin{array}{l}\text { "That was probably the worse asthma attack I } \\
\text { had in my life.. I almost died if it wasn't for this } \\
\text { (cont) http://t.co/Ox2UcqHB" }\end{array}$ & 34 & 4.0 \\
\hline 9 & $\begin{array}{l}\text { Feelings about } \\
\text { symptoms, asthma, or } \\
\text { asthma attack }\end{array}$ & $\begin{array}{l}\text { Sharing thoughts, concerns, } \\
\text { frustrations about asthma, } \\
\text { symptoms or having an attack. Also } \\
\text { seeking validation from others }\end{array}$ & $\begin{array}{l}\text { "Asthma Treatment: When you are an asthmatic, } \\
\text { having an asthma attack is one of your worse } \\
\text { fears. You become scared.." }\end{array}$ & 6 & 0.7 \\
\hline 10 & General treatment & $\begin{array}{l}\text { General information or mention } \\
\text { about asthma treatment (not specific } \\
\text { to pharmaceutical or } \\
\text { complementary and alternative } \\
\text { treatment) }\end{array}$ & $\begin{array}{l}\text { "Could anyone suggest me the best treatment one } \\
\text { can have for asthma in New Delhi.?: Could any } \\
\text { person advise me the.." }\end{array}$ & 95 & 11.2 \\
\hline 11 & $\begin{array}{l}\text { Pharmaceutical } \\
\text { treatment }\end{array}$ & $\begin{array}{l}\text { Discussions and inquiry about types } \\
\text { of Pharmaceutical treatments for } \\
\text { asthma; includes: inhalers or OTC, } \\
\text { promotions of specific treatments, } \\
\text { mentions of FDA }\end{array}$ & $\begin{array}{l}\text { "Inhaled epinephrine is not a good treatment for } \\
\text { asthma_today," says PA Nancy McKemie. } \\
\text { _Asthma_is a disease of.." }\end{array}$ & 65 & 7.7 \\
\hline 12 & $\begin{array}{l}\text { Using pharmaceutical } \\
\text { treatment }\end{array}$ & $\begin{array}{l}\text { Learning how to properly use } \\
\text { pharmaceutical treatment, including } \\
\text { inhalers, dosing, etc. }\end{array}$ & $\begin{array}{l}\text { "Moms of kids with asthma: how do you do } \\
\text { inhaler treatments without ripping your hair out? } \\
\text { My } 4 \text { year old refuses to breathe the meds in :(“ }\end{array}$ & 7 & 0.8 \\
\hline 13 & $\begin{array}{l}\text { Mechanism of Action } \\
\text { (MOA) }\end{array}$ & Learn how the medicine works & & 0 & 0 \\
\hline 14 & Treatment side effects & $\begin{array}{l}\text { Any mention or concerns of side } \\
\text { effects resulting from treatment }\end{array}$ & $\begin{array}{l}\text { "Asthma and its treatment: Higher doses can } \\
\text { result in typical steroid side effects of; weight } \\
\text { gain, lowering the .." }\end{array}$ & 4 & 0.5 \\
\hline 15 & Treatment outcomes & $\begin{array}{l}\text { Any mention or concern about the } \\
\text { outcomes of treatment (not related } \\
\text { to quality of life). Examples: } \\
\text { benefits, efficacy, results }\end{array}$ & $\begin{array}{l}\text { "@asthmauk you guys rock.Really feeling it with } \\
\text { my asthma lately,brown inhaler doesnt seem } 2 \text { b } \\
\text { helping much. if only a cure were imminent!” }\end{array}$ & 6 & 0.7 \\
\hline
\end{tabular}




\begin{tabular}{|c|c|c|c|c|c|}
\hline \# & Category & Thematic description & Example & $\begin{array}{l}\text { Number of } \\
\text { Tweets }\end{array}$ & $\begin{array}{l}\text { Percent } \\
\text { age }\end{array}$ \\
\hline 16 & $\begin{array}{l}\text { Complementary and } \\
\text { alternative treatment }\end{array}$ & $\begin{array}{l}\text { Discuss alternative treatment } \\
\text { options to pharmaceuticals. Some } \\
\text { examples include yoga and home } \\
\text { remedies. }\end{array}$ & $\begin{array}{l}\text { "YogaBugs issues news release about new } \\
\text { research showing that yoga helps adolescents } \\
\text { deal with asthma symptoms." }\end{array}$ & 92 & 10.9 \\
\hline 17 & Quality of life & $\begin{array}{l}\text { Negative and positive lifestyle } \\
\text { effects: missed school days/work, } \\
\text { effect on day-to-day activities, } \\
\text { unable to participate in activities, } \\
\text { improvements, life changes }\end{array}$ & $\begin{array}{l}\text { "I have a lead part in our school play will will } \\
\text { rock you. And I have very bad_asthma_so what } \\
\text { can I dolsay if I.." }\end{array}$ & 5 & 0.6 \\
\hline 18 & $\begin{array}{l}\text { Asthma and comorbid } \\
\text { condition }\end{array}$ & $\begin{array}{l}\text { Discusses asthma affecting another } \\
\text { condition or vice versa }\end{array}$ & $\begin{array}{l}\text { "Depressive symptoms may make asthma control } \\
\text { more difficult: (Medical Xpress) -- People with } \\
\text { asthma are more li" }\end{array}$ & 4 & 0.5 \\
\hline 19 & Death & Death due to asthma attack & $\begin{array}{l}\text { "SaïdouGadiaga, a Senegalese citizen for } 37 \\
\text { years, died of an asthma attack without having } \\
\text { received aid from the.." }\end{array}$ & 10 & 1.2 \\
\hline 20 & Pregnancy & $\begin{array}{l}\text { Information and concerns about } \\
\text { asthma, symptoms, and treatment } \\
\text { during pregnancy }\end{array}$ & $\begin{array}{l}\text { "\#asthma medicine and pregnancy:Visit your } \\
\text { doctor soon after realizing that you are pregnant } \\
\text { to discuss about the... http://t.co/UAMrW1pr" } \\
\text { "Technology and Health: Text Message }\end{array}$ & 4 & 0.5 \\
\hline 21 & Programs and services & Asthma programs and services & $\begin{array}{l}\text { Reminders Prompt Kids to Take Asthma } \\
\text { Medicine http://t.co/oUE1SnpJ" }\end{array}$ & 25 & 3.0 \\
\hline 22 & Joke & $\begin{array}{l}\text { Using the terms asthma or asthma } \\
\text { attack as a joke }\end{array}$ & $\begin{array}{l}\text { "clearly@ladygaga was the best live performer } \\
\text { out of all those nominees ... @ @ katyperry sounds } \\
\text { like an asthma attack waiting to happen -_-“ }\end{array}$ & 28 & 3.3 \\
\hline 23 & Stigma & $\begin{array}{l}\text { Negative social perceptions of } \\
\text { asthma }\end{array}$ & $\begin{array}{l}\text { "When you KNOW a person has asthma they } \\
\text { forever breathe all hard on the phone, but they } \\
\text { always wanna deny it \& not purchase a inhaler } \\
<\text { lmfao" }\end{array}$ & 4 & 0.5 \\
\hline 24 & Other & $\begin{array}{l}\text { Tweets that do not fall in the } \\
\text { categories listed, or tweets that are } \\
\text { not interpretable but mention } \\
\text { asthma }\end{array}$ & $\begin{array}{l}\text { "BREATHE- A Short Film about_ASTHMA_, } \\
\text { devised by the pupils of Auchinairn Primary } \\
\text { School, Bishopbriggs, Glasgow..." }\end{array}$ & 62 & 7.3 \\
\hline
\end{tabular}

*Note: Percentages do not add up to $100 \%$ due to rounding

\section{Limitations and Future Directions}

There are a few limitations that should be considered. The intercoder reliability reported in this study was acceptable; however, it is lower than in other studies for several reasons. First, the short nature of tweets (140 characters maximum) can make it difficult to analyze and assign a theme. Secondly, tweets may be in response to other tweets which means that the context is lost when coding.

Another weakness of using Twitter as a main data source is that segmentation of the subject pool cannot be accurately performed. Due to the fact that demographic information is not uniformly collected from Twitter, researchers cannot analyze to see if there are differences by subject type. For example, there is not a way to know if women tweet more about a certain topic than men.

One consideration when using Twitter as a research tool is that one should take care when selecting a data range to analyze. If there is a national news story or relevant event during the same time period it can influence the content of the tweets and, therefore, bias the results.

A follow-up study may look to interview people who tweet about asthma or other health conditions to gain deeper insight into why they tweet and what they tweet about.

Further, this study only considered those who are tweeting. There are many others who may be reading tweets about a particular topic but not retweeting. Therefore, it would also be helpful to include these types of subjects in the study to gain information about how they use twitter for health information. Despite this limitation, this study did show how Twitter can be utilized in the future as a research tool.

\section{References}

[1] National Asthma Education and Prevention Program (NAEPP). Expert Panel Report 3: Guidelines for the Diagnosis and Management of Asthma. National Heart, Lung, and Blood Institute (NHLBI) Health Information Center, 2007.

[2] World Health Organization (WHO). Global surveillance, prevention and control of Chronic Respiratory Diseases, 2007.

[3] World Health Organization (WHO), 2012. From: http://www.who.int/respiratory/asthma/en/ 
[4] Centers for Disease Control and Prevention (CDC), Vital Signs: Asthma Prevalence, Disease Characteristics, and Self-Management Education - United States, 2001-2009. Morbidity and Mortality Weekly Report (CDC) vol, 60(17),2011.

[5] R.J. Adams, E.T. d'Espaigne, E. Dal Grande, A. Daly, R.E. Ruffin, A.W. Taylor, and D.H. Wilson, Psychological factors and asthma quality of life: a population based study, Thorax, vol. 59, pp. 930-935, 2004.

[6] E. Pereira, A. Cavalcante, ENS. Pereira, P. Lucas, M.A. Holanda, JornalBrasileiro de Pneumologia, vol. 37 (6), pp. 705-711, 2011.

[7] World Health Organization (WHO), Asthma, 2012From: http://www.who.int/mediacentre/factsheets/fs307/en/index.h tml

[8] M. Leander, E.Lampa, C.Janson, K.Svärdsudd, M. Uddenfeldt, A. Rask, and A. Andersen, Determinants for a low health-related quality of life in asthmatics, Upsala Journal of Medical Sciences, vol. 117, pp. 57-66, 2012.

[9] National Heart, Lung, and Blood Institute, 2012.

[10] A.V, Joshi, et al, Association of mediation adherence with workplace productivity and health-related quality of life in patients with asthma, Journal of Asthma, vol. 43, pp. 521526, 2006

[11] A. Gillissen, Patients' adherence in asthma, Journal of Physiology and Pharmacology, vol. 58, pp. 205-222, 2007.

[12] C.S. Ulrik, et al, The patient's perspective: adherence or non-adherence to asthma controller therapy? Journal of Asthma, vol. 43, pp. 701-704, 2006.

[13] NHS Institute for Innovation and Improvement 2006-2012, Patient Perspectives, 2012.
[14] Quality and service improvement tools. From: http://www.institute.nhs.uk/quality_and_service_improveme nt tools/quality and service improvement tools/patient pe rspectives.html

[15] S. McPhail, and T. Haines, Response shift, recall bias and their effect on measuring change in health- related quality of life amongst older hospital patients, Health and Quality of Life Outcome, vol. 8(65), 2010.

[16] F. J. Gravetter, and L.B. Forzano, Research methods for the behavioral sciences (4th Edition), Wadsworth Cengage Learning, 2012. From: http://www.nhlbi.nih.gov /health/health-topics/topics/asthma/treatment.html

[17] K. Sajadi, and H. Goldman, Social networks lack useful content for incontinence, Urology, vol. 78, pp. 764-767, 2011.

[18] K. Ogburn, E.Messias, and P. Buckley, New-age patient communications through social networks, General Hospital Psychiatry, vol. 33, pp. 1-3, 2011.

[19] J. Kietzmann, K.Hermkens, I. McCarthy, and B. Silvestre, Social media? Get serious! Understanding the functional building blocks of social media, Business Horizons, vol. 54, pp. $241-251,2011$.

[20] Twitter, 2012.From: www.twitter.com

[21] Mashable, The Twitter Guide Book, 2012. From: http://mashable.com/guidebook/twitter

[22] ComScore,ComScore introduces Mobile Metrix 2.0, revealing that social media brands experience heavy engagement on smartphones, 2012. From: http://www.comscore.com/Press_Events/Press_Releases/201 2/5/Introducing_Mobile_Metrix_2_Insight_into_Mobile_Be havior

[23] G. Guest, K.M. MacQueen, and E.E. Namey, 2012. 